\title{
Agentes osmóticos e temperatura na conservação in vitro de sempre-viva
}

\author{
Osmotic agents and temperature on in vitro conservation of sempre-viva
}

\begin{abstract}
Alone Lima- Brito ${ }^{\mathrm{I}}$ Mara Márcia Sampaio Albuquerque ${ }^{\mathrm{II}}$ Bruno Freitas Matos Alvim ${ }^{\mathrm{II}}$ Sheila Vitória Resende ${ }^{\text {III }}$ Moema Cortizo Bellintani ${ }^{\text {III }}$ José Raniere Ferreira de Santana $^{\text {IV }}$
\end{abstract}

RESUMO

A conservação in vitro é uma estratégia de conservação ex situ que garante a manutenção da integridade genética e biológica das espécies. O objetivo deste estudo foi avaliar o efeito de agentes osmóticos e temperatura na conservação in vitro de Syngonanthus mucugensis Giul. subsp. mucugensis. Os brotos foram inoculados em meio de cultura MS $1 / 2$ contendo $7 \mathrm{~g} \mathrm{~L}^{-1}$ de ágar e suplementado com $60 \mathrm{~g} \mathrm{L^{-1 }}$ de sacarose, e com as concentrações de sacarose 15, 30 e $45 \mathrm{~g} \mathrm{~L}^{-1}$ combinados com 0 e $15 \mathrm{~g} \mathrm{~L}^{-1}$ de sorbitol ou manitol. As culturas foram mantidas em duas temperaturas $\left(18\right.$ e $\left.25^{\circ} \mathrm{C}\right)$. A porcentagem de sobrevivência das plantas foi avaliada mensalmente e ao final de 180 dias foram analisados o comprimento da parte aérea e da raiz, a porcentagem de folhas verdes, a porcentagem de explantes com brotos, o número de brotos por explante e o comprimento dos brotos. Os agentes osmóticos promoveram um decréscimo no crescimento das plantas, no entanto reduziram a sua viabilidade. Os resultados observados nos experimentos mantidos a $18^{\circ} \mathrm{C}$ foram significativamente superiores aos encontrados a $25^{\circ}$, para todas as variáveis analisadas. A conservação de $\boldsymbol{S}$. mucugensis subsp. mucugensis pode ser feita à $18^{\circ} \mathrm{C}$ em meio de cultura MS $1 / 2$ contendo $15 \mathrm{~g} \mathrm{~L}^{-1}$ de sacarose, por até 180 dias, sem subcultivo.

Palavras-chave: Syngonanthus mucugensis subsp. mucugensis, crescimento mínimo, cultura in vitro, conservação ex situ.

\section{ABSTRACT}

The in vitro conservation is an ex situ conservation strategy that ensures the maintenance of genetic and biological integrity of species. The present study evaluated the effects of, osmotic agents and different temperature regimes on the in vitro conservation of Syngonanthus mucugensis Giul. subsp. mucugensis. The shoots were inoculated into half salt strength Murashige and Skoog culture medium (MS 1/2) containing $7 \mathrm{~g} \mathrm{~L}^{-1}$ of agar. The culture medium was supplemented with $60 \mathrm{gL}^{-1}$ sucrose and with the sucrose concentrations 15, 30 and $45 \mathrm{~g} \mathrm{~L}^{-1}$ combined with 0 and $15 \mathrm{~g} \mathrm{~L}^{-1}$ of sorbytol or mannitol. Two different temperatures were used in these experiments $\left(18\right.$ and $\left.25^{\circ} \mathrm{C}\right)$. The percentage of plant survival was evaluated monthly and at 180 days were analyzed length of shoot and root, the percentage of green leaves, the percentage of explants with shoots and number of shoots per explants and shoot length. The addition of osmotic agents resulted in decreased growth of the plants and therefore reduced their viability. The averages observed in the experiments undertaken at $18^{\circ} \mathrm{C}$ were significantly superior to those observed at $25^{\circ} \mathrm{C}$ for all of the variables analyzed. S. mucugensis subsp. mucugensis can be cultured at $18^{\circ} \mathrm{C}$ in $M S^{1 / 2}$ culture medium containing $15 \mathrm{~g} \mathrm{~L}^{-1}$ of sucrose, for up to 180 days, without subculturing.

Key words: Syngonanthus mucugensis subsp. mucugensis, minimal growth, in vitro culture, ex situ conservation.

\section{INTRODUÇÃO}

Syngonanthus mucugensis Giul. subsp. mucugensis, conhecida como sempre-viva de mucugê, é uma herbácea ornamental endêmica do município de

'Programa de Pós-graduação em Botânica, Universidade Estadual de Feira de Santana (UEFS), 44036-336, Feira de Santana, BA, Brasil. E-mail: lima_brito@yahoo.com.br. Autor para correspondência.

"Programa de Pós-graduação em Recursos Genéticos Vegetais, UEFS, Feira de Santana, BA, Brasil.

IIIInstituto de Biologia, Universidade Federal da Bahia (UFBA), Salvador, BA, Brasil.

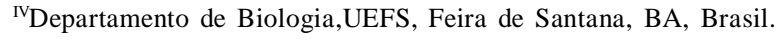


Mucugê, na Chapada Diamantina, BA, Brasil. Essa espécie encontra-se ameaçada de extinção devido à exploração extrativista de suas flores para o mercado florístico (GIULIETTI et al., 1996; CERQUEIRA et al., 2008).

A conservação de sempre-viva de mucugê tem se restringido à preservação em seu ambiente natural no Parque Nacional da Chapada Diamantina. Isso torna necessária a utilização de técnicas complementares de conservação ex situ para manter a diversidade genética dessa espécie.

A conservação in vitro baseia-se no cultivo das coleções em laboratório, a partir das técnicas de cultura de tecidos vegetais; as quais garantem a manutenção da integridade genética e biológica de um elevado número de acessos em espaço reduzido, além de promover altas taxas de multiplicação em condições assépticas e permitir o intercâmbio de germoplasma (ENGELMANN, 1991; VILLALOBOS et al., 1991; GEORGE, 1993; FAY, 1994; RAO, 2004; FARIA et al., 2006; SARASAN et al., 2006).

A restrição do crescimento in vitro é uma técnica vantajosa, porque aumenta o período entre os subcultivos, reduz os custos com a manutenção do banco ativo de germoplasma e, principalmente, minimiza os riscos de alteração genética e contaminação (ENGELMANN, 1991; VILLALOBOS et al., 1991; LEMOS et al., 2002). Esse método tem sido aplicado com sucesso para a conservação de espécies ornamentais ameaçadas de extinção, a exemplo da orquídea Ipsea malabarica (Reichb.f.) J. D. Hook e das bromélias Dyckia distachya Hassler e Vriesea inflata (Wawra) Wawra (MARTIN \& PRADEEP, 2003; POMPELI \& GUERRA, 2004; PEDROSO et al., 2010).

O crescimento mínimo consiste em reduzir o metabolismo vegetal por alterações no ambiente de cultivo, como, decréscimo na intensidade da luz, fotoperíodo, trocas gasosas e temperatura de incubação da cultura, e por modificações no meio de cultura por meio da adição de reguladores vegetais e agentes osmóticos e redução dos componentes salinos e orgânicos (ENGELMANN, 1991; VILLALOBOS et al., 1991; WITHERS \& WILLIANS, 1998; LEMOS et al., 2002).

O decréscimo da temperatura é uma das estratégias mais utilizadas para manter as plantas em crescimento mínimo por reduzir o metabolismo da planta, incluindo alterações no conteúdo e ação das enzimas e na composição e funcionamento das membranas celulares (LEMOS et al., 2002; LÉDO et al., 2007). Essa técnica tem sido utilizada para a conservação de diversas espécies vegetais, com respostas que variam em função da sensibilidade à baixa temperatura
(NEGASH et al., 2001; LEMOS et al., 2002; FARIA et al., 2006). A combinação de baixas temperaturas com a adição de reguladores vegetais ou agentes osmóticos no meio de cultura tem sido apontada como uma alternativa eficiente para a conservação de germoplasma in vitro.

Os agentes osmóticos como a sacarose, o manitol e o sorbitol, agem sobre o crescimento reduzindo o potencial hídrico do meio de cultura e consequentemente inibindo a absorção de água e nutrientes pelo explante (CALDAS et al., 1998; ENGELMANN, 1991; LÉDO et al., 2007).

O objetivo deste estudo foi avaliar o efeito de agentes osmóticos e temperatura na conservação in vitro de brotos micropropagados de $S$. mucugensis subsp. mucugensis.

\section{MATERIAL E MÉTODOS}

Material vegetal e meio de cultura

Foram utilizados como explante brotos com aproximadamente $10 \mathrm{~mm}$ de comprimento, obtidos por organogênese direta conforme metodologia descrita por LIMA-BRITO et al. (2011).

Os explantes foram inoculados em tubos de ensaio $(25 \times 150 \mathrm{~mm})$ contendo $15 \mathrm{~mL}$ de meio de cultura MS (MURASHIGE \& SKOOG, 1962) com metade da concentração salina (MS 1/2), gelificado com $7 \mathrm{~g} \mathrm{~L}^{-1} \mathrm{de}$ agar. $\mathrm{O} \mathrm{pH}$ do meio foi ajustado para 5,7 antes da autoclavagem, realizada à $121^{\circ} \mathrm{C}$ por 15 minutos.

Agentes osmóticos e temperatura

O meio de cultura foi suplementado com $60 \mathrm{~g}$ $\mathrm{L}^{-1}$ de sacarose com potencial osmótico $(\Psi \mathrm{o})$ $0,4340 \mathrm{MPa}$ e com as concentrações de sacarose 15,30 e $45 \mathrm{~g} \mathrm{~L}^{-1}$ (correspondendo aos $\Psi \mathrm{o}-0,1085,-0,2170 \mathrm{e}$ $0,3255 \mathrm{MPa}$, respectivamente), combinados com $0 \mathrm{e}$ $15 \mathrm{gL}^{-1}\left(\Psi_{\mathrm{O}}=-0,1085 \mathrm{MPa}\right)$ de sorbitol ou manitol, constituindo os seguintes tratamentos: $\mathrm{T} 1-15 \mathrm{~g} \mathrm{~L}^{-1} \mathrm{de}$ sacarose; T2- 30 $\mathrm{g} \mathrm{L}^{-1}$ de sacarose; T3- $45 \mathrm{~g} \mathrm{~L}^{-1}$ de sacarose; T4- 60g L $\mathrm{g}^{-1}$ de sacarose; $\mathrm{T} 5-15 \mathrm{~g} \mathrm{~L}^{-1} \mathrm{de}$ sacarose $+15 \mathrm{~g} \mathrm{~L}^{-1}$ de sorbitol; T6- $30 \mathrm{~g} \mathrm{~L}^{-1}$ de sacarose $+15 \mathrm{~g} \mathrm{~L}^{-1}$ de sorbitol; $\mathrm{T} 7-45 \mathrm{~g} \mathrm{~L}^{-1}$ de sacarose $+15 \mathrm{~g} \mathrm{~L}^{-1}$ de sorbitol; $\mathrm{T} 8-15 \mathrm{~g} \mathrm{~L}^{-1}$ de sacarose $+15 \mathrm{~g} \mathrm{~L}^{-1}$ de manitol; T9-30g L ${ }^{-1}$ de sacarose $+15 \mathrm{~g} \mathrm{~L}^{-1}$ de manitol; e T10- $45 \mathrm{~g}$ $\mathrm{L}^{-1}$ de sacarose $+15 \mathrm{~g} \mathrm{~L}^{-1}$ de manitol.

As culturas foram mantidas em câmara do tipo B.O.D. a $18^{\circ} \mathrm{C}$ e em sala de crescimento a $25 \pm 3^{\circ} \mathrm{C}$. O delineamento experimental foi o DIC em arranjo fatorial 10x2 (agente osmótico x temperatura), com dez repetições e quatro tubos por repetição (um explante por tubo).

A porcentagem de sobrevivência $(\% \mathrm{~S})$ foi avaliada mensalmente e aos 180 dias de armazenamento 
foram analisados: comprimento da parte aérea (CPA), comprimento da raiz (CR), porcentagem de folhas verdes $(\% \mathrm{FV})$, porcentagem de explantes com brotos $(\% \mathrm{~B})$, número de brotos por explante (NB) e comprimento dos brotos (CB).

\section{Análise estatística}

Os dados foram submetidos à análise de variância e, quando significativo, as médias foram submetidas ao teste de Scott-Knott a $5 \%$ de probabilidade. Utilizou-se o software Sisvar 4.3 (FERREIRA, 2003).

\section{RESULTADOS E DISCUSSÃO}

A interação "agente osmótico x temperatura" foi significativa para as variáveis comprimento da parte aérea e da raiz e porcentagem de sobrevivência e de folhas verdes (Tabela 1). Isso demonstra que diferentes fatores químico e físicos podem interagir entre si na conservação das plantas in vitro, o que justifica a importância de serem testados conjuntamente (GEORGE, 1993; SARKAR \& NAIK, 1998). Observou-se efeito isolado do agente osmótico e da temperatura para porcentagem de explantes com brotos, número de brotos por explante e comprimento dos brotos (Tabela 2).

Nas plantas mantidas a $18^{\circ} \mathrm{C}$, não houve diferenças significativas entre 15 e $30 \mathrm{~g} \mathrm{~L}^{-1}$ de sacarose para comprimento da parte aérea $(27,30$ e $23,40 \mathrm{~mm}$, respectivamente) e comprimento da raiz $(28,70$ e $23,40 \mathrm{~mm}$, respectivamente), sendo observada uma redução dessas variáveis com o aumento da concentração de sacarose para 45 e $60 \mathrm{~g} \mathrm{~L}^{-1}$ (Tabela 1). Esses resultados indicam que a sacarose, quando utilizada em altas concentrações, diminui o potencial hídrico do meio de cultura, o que inibe a absorção de água e nutrientes pelo explante, reduzindo o crescimento in vitro (ENGELMANN, 1991; CALDAS et al., 1998).

O decréscimo no comprimento da parte aérea e no comprimento da raiz em resposta ao aumento na concentração de sacarose também foi observado a $25^{\circ} \mathrm{C}$ de temperatura. As maiores médias para essas variáveis foram encontradas no tratamento com $15 \mathrm{~g} \mathrm{~L}^{-1} \mathrm{de}$ sacarose (Tabela 1), corroborando os resultados relatados por SILVA et al. (2005), que obtiveram melhores taxas de crescimento de plantas de $S$. mucugensis in vitro a $25^{\circ} \mathrm{C}$ em meio contendo $15 \mathrm{~g} \mathrm{~L}^{-1}$ de sacarose, quando comparado com as concentrações 20 e $30 \mathrm{~g} \mathrm{~L}^{-1}$.

Nos tratamentos suplementados com a combinação de sacarose com sorbitol ou manitol, também foi observada uma redução das variáveis comprimento da parte aérea e da raiz, à medida que houve aumento na concentração total de carboidratos no meio, tanto a $18^{\circ} \mathrm{C}$ como a $25^{\circ} \mathrm{C}$ de temperatura (Tabela 1).

Comparando os tipos de agentes osmóticos, nas duas temperaturas testadas, não foram observadas diferenças significativas para comprimento da parte aérea entre os meios suplementados com sacarose e sacarose + sorbitol tanto na concentração total de $30 \mathrm{~g}$ $\mathrm{L}^{-1}$ como de $45 \mathrm{~g} \mathrm{~L}^{-1}$. Os resultados obtidos nesses tratamentos foram significativamente superiores aos que utilizaram o carboidrato manitol. Nas duas temperaturas testadas, as menores médias para comprimento da parte aérea foram obtidas na concentração total de $60 \mathrm{~g} \mathrm{~L}^{-1}$ sem diferenças significativas entre os tipos de carboidratos utilizados, não diferindo de $45 \mathrm{~g} \mathrm{~L}^{-1}$ a $25^{\circ} \mathrm{C}$ (Tabela 1).

O sorbitol e o manitol são açúcares alcoóis que geralmente não são metabolizados pelas plantas e por isso são empregados para a redução do potencial hídrico do meio de cultura na conservação in vitro (GEORGE, 1993). Para S. mucugensis subsp. mucugensis, o manitol mostrou-se mais eficiente que o sorbitol na redução do crescimento das plantas, corroborando os resultados obtidos para Solanum tuberosum L., Vanilla sp. e Cocos nucifera L. (FORTES \& PEREIRA, 2001; DIVAKARAN et al., 2006; LÉDO et al., 2007).

Para comprimento da raiz, não foram observadas diferenças significativas entre os tratamentos com sacarose, sacarose + sorbitol e sacarose + manitol, nas duas temperaturas, comparando-se as concentrações totais de carboidratos. As plantas mantidas a $25^{\circ} \mathrm{C}$ apresentaram maiores valores para esta variável em $15 \mathrm{~g} \mathrm{~L}^{-1} \mathrm{de}$ sacarose, que diferiu significativamente dos demais tratamentos (Tabela 1).

O decréscimo do comprimento da parte aérea e da raiz de $\boldsymbol{S}$. mucugensis subsp. mucugensis, em resposta à redução do potencial hídrico do meio de cultura, corrobora os resultados obtidos para Drosophyllum lusitanicum (L.) Link. e C. nucifera conservadas in vitro (GONÇALVES \& ROMANO, 2007; LÉDO et al., 2007). No entanto, o aumento da concentração de carboidratos no meio não é indicado para a conservação in vitro de $S$. mucugensis subsp. mucugensis, visto que reduziu a viabilidade das plantas.

Aos 30 dias de conservação, não foram encontradas diferenças significativas entre os tratamentos para a porcentagem de sobrevivência nas duas temperaturas testadas. A partir de 60 dias de observação, houve uma redução dessa variável, especialmente nos meios com maior concentração de 
Tabela 1 - Efeito de diferentes concentrações dos agentes osmóticos sacarose, sorbitol e manitol no comprimento da parte aérea (CPA) e do sistema radicular (CR) e na porcentagem de sobrevivência $(\% \mathrm{~S})$ e de folhas verdes $(\% \mathrm{FV})$ das plantas de Syngonanthus mucugensis subsp. mucugensis conservadas in vitro durante 180 dias, em duas temperaturas: 18 e $25^{\circ} \mathrm{C}$.

\begin{tabular}{|c|c|c|c|c|c|}
\hline \multicolumn{4}{|c|}{--10 } & \multicolumn{2}{|c|}{ 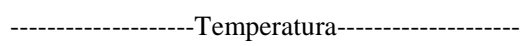 } \\
\hline & & & & $----18^{\circ} \mathrm{C}-----$ & $-----25^{\circ} \mathrm{C}-----$ \\
\hline Sacarose & Sorbitol & Manitol & Total & \multicolumn{2}{|c|}{ 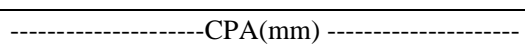 } \\
\hline 15 & - & - & 15 & $27,30 \mathrm{~A} \mathrm{a}$ & $25,80 \mathrm{~A} \mathrm{a}$ \\
\hline 30 & - & - & 30 & $23,40 \mathrm{~A} \mathrm{a}$ & $15,20 \mathrm{~B} \mathrm{~b}$ \\
\hline 45 & - & - & 45 & $12,50 \mathrm{~B} \mathrm{a}$ & $3,70 \mathrm{Cb}$ \\
\hline 60 & - & - & 60 & $6,90 \mathrm{D} \mathrm{a}$ & $0,00 \mathrm{D} \mathrm{b}$ \\
\hline 15 & 15 & - & 30 & $21,70 \mathrm{~A} \mathrm{a}$ & $15,70 \mathrm{~B} \mathrm{~b}$ \\
\hline 30 & 15 & - & 45 & $17,50 \mathrm{~B} \mathrm{a}$ & $5,50 \mathrm{Cb}$ \\
\hline 45 & 15 & - & 60 & $6,20 \mathrm{D} \mathrm{a}$ & $0,00 \mathrm{D} \mathrm{b}$ \\
\hline 15 & - & 15 & 30 & $15,90 \mathrm{~B} \mathrm{a}$ & $3,40 \mathrm{Cb}$ \\
\hline 30 & - & 15 & 45 & $12,60 \mathrm{Ca}$ & $0,30 \mathrm{D} \mathrm{b}$ \\
\hline 45 & - & 15 & 60 & $4,50 \mathrm{D} \mathrm{a}$ & $0,40 \mathrm{D} \mathrm{b}$ \\
\hline 15 & - & - & 15 & $28,70 \mathrm{~A} \mathrm{a}$ & $22,50 \mathrm{~A} \mathrm{a}$ \\
\hline 30 & - & - & 30 & $23,40 \mathrm{~A} \mathrm{a}$ & $7,90 \mathrm{~B} \mathrm{~b}$ \\
\hline 45 & - & - & 45 & $12,50 \mathrm{~B} \mathrm{a}$ & $2,70 \mathrm{Cb}$ \\
\hline 60 & - & - & 60 & $7,00 \mathrm{C} \mathrm{a}$ & $0,00 \mathrm{D} \mathrm{b}$ \\
\hline 15 & 15 & - & 30 & $24,70 \mathrm{~A} \mathrm{a}$ & $10,80 \mathrm{~B} \mathrm{~b}$ \\
\hline 30 & 15 & - & 45 & $18,80 \mathrm{~B} \mathrm{a}$ & $3,30 \mathrm{Cb}$ \\
\hline 45 & 15 & - & 60 & $4,30 \mathrm{C} \mathrm{a}$ & $0,00 \mathrm{Db}$ \\
\hline 15 & - & 15 & 30 & $26,00 \mathrm{~A} \mathrm{a}$ & $6.00 \mathrm{~B} \mathrm{~b}$ \\
\hline 30 & - & 15 & 45 & $18,20 \mathrm{~B} \mathrm{a}$ & $2,50 \mathrm{Cb}$ \\
\hline 45 & - & 15 & 60 & $5,00 \mathrm{C} \mathrm{a}$ & $0,00 \mathrm{Db}$ \\
\hline & & & & $\mathrm{S}(\%)$ & \\
\hline 15 & - & - & 15 & $97,5 \mathrm{~A} \mathrm{a}$ & $89,0 \mathrm{~A} \mathrm{~b}$ \\
\hline 30 & - & - & 30 & $97,5 \mathrm{~A} \mathrm{a}$ & $65,0 \mathrm{~B} \mathrm{~b}$ \\
\hline 45 & - & - & 45 & $68,0 \mathrm{~B} \mathrm{a}$ & $20,0 \mathrm{Cb}$ \\
\hline 60 & - & - & 60 & $42,5 \mathrm{C} \mathrm{a}$ & $0,0 \mathrm{D} \mathrm{b}$ \\
\hline 15 & 15 & - & 30 & $92,5 \mathrm{~A} \mathrm{a}$ & $65,0 \mathrm{~B} \mathrm{~b}$ \\
\hline 30 & 15 & - & 45 & $65,0 \mathrm{~B} \mathrm{a}$ & $25,0 \mathrm{Cb}$ \\
\hline 45 & 15 & - & 60 & $25,0 \mathrm{C} \mathrm{a}$ & $2,5 \mathrm{D} \mathrm{b}$ \\
\hline 15 & - & 15 & 30 & $90,0 \mathrm{~A} \mathrm{a}$ & $17,5 \mathrm{Cb}$ \\
\hline 30 & - & 15 & 45 & $60,0 \mathrm{~B} \mathrm{a}$ & $2,5 \mathrm{D} \mathrm{b}$ \\
\hline 45 & - & 15 & 60 & $22,5 \mathrm{C} \mathrm{a}$ & $2,5 \mathrm{D} \mathrm{b}$ \\
\hline 15 & - & - & 15 & $89,1 \mathrm{~A} \mathrm{a}$ & $69,7 \mathrm{~A} \mathrm{~b}$ \\
\hline 30 & - & - & 30 & $71,7 \mathrm{~A} \mathrm{a}$ & $31,9 \mathrm{~B} \mathrm{~b}$ \\
\hline 45 & - & - & 45 & $34,2 \mathrm{~B} \mathrm{a}$ & $6,2 \mathrm{C} \mathrm{b}$ \\
\hline 60 & - & - & 60 & $15,0 \mathrm{C} \mathrm{a}$ & $0,0 \mathrm{D} \mathrm{b}$ \\
\hline 15 & 15 & - & 30 & $73,9 \mathrm{~A} \mathrm{a}$ & $25,0 \mathrm{~B} \mathrm{~b}$ \\
\hline 30 & 15 & - & 45 & $38,1 \mathrm{~B} \mathrm{a}$ & $8,1 \mathrm{C} \mathrm{b}$ \\
\hline 45 & 15 & - & 60 & $9,3 \mathrm{C} \mathrm{a}$ & $0,0 \mathrm{D} \mathrm{b}$ \\
\hline 15 & - & 15 & 30 & $51,4 \mathrm{~B} \mathrm{a}$ & $4,4 \mathrm{C} \mathrm{b}$ \\
\hline 30 & - & 15 & 45 & $27,2 \mathrm{~B} \mathrm{a}$ & $0,6 \mathrm{D} \mathrm{b}$ \\
\hline 45 & - & 15 & 60 & $8,7 \mathrm{C} \mathrm{a}$ & $0,6 \mathrm{D} \mathrm{b}$ \\
\hline
\end{tabular}

Médias seguidas pela mesma letra, maiúsculas nas colunas e minúsculas nas linhas, não diferem significativamente entre si pelo teste ScottKnott a $5 \%$ de probabilidade. 
Tabela 2 - Efeito de diferentes concentrações dos agentes osmóticos sacarose, sorbitol e manitol na porcentagem de plantas com brotos (\%B), número de brotos por planta (NB) e comprimento dos brotos (CB) de S. mucugensis subsp. mucugensis conservadas in vitro durante 180 dias, em duas temperaturas: 18 e $25^{\circ} \mathrm{C}$.

\begin{tabular}{|c|c|c|c|c|c|}
\hline & \multirow[b]{3}{*}{ Sorbitol } & \multirow[b]{3}{*}{ Manitol } & \multirow[b]{3}{*}{ Total } & \multicolumn{2}{|c|}{ 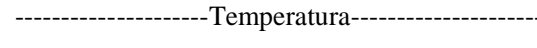 } \\
\hline \multirow[b]{2}{*}{ Sacarose } & & & & $---18^{\circ} \mathrm{C}----$ & $---25^{\circ} \mathrm{C}-$ \\
\hline & & & & \multicolumn{2}{|c|}{ 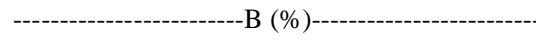 } \\
\hline 15 & - & - & 15 & $7,5 \mathrm{Ca}$ & $2,5 \mathrm{Cb}$ \\
\hline 30 & - & - & 30 & $10,0 \mathrm{C} \mathrm{a}$ & $2,5 \mathrm{Cb}$ \\
\hline 45 & - & - & 45 & $12,5 \mathrm{C} \mathrm{a}$ & $7,5 \mathrm{~B} \mathrm{~b}$ \\
\hline 60 & - & - & 60 & $2,5 \mathrm{C} \mathrm{a}$ & $0,0 \mathrm{D} \mathrm{b}$ \\
\hline 15 & 15 & - & 30 & $22,5 \mathrm{~B}$ a & $12,5 \mathrm{Ab}$ \\
\hline 30 & 15 & - & 45 & $37,5 \mathrm{~A} \mathrm{a}$ & $15,0 \mathrm{~A} \mathrm{~b}$ \\
\hline 45 & 15 & - & 60 & $7,5 \mathrm{C} \mathrm{a}$ & $0,0 \mathrm{Db}$ \\
\hline 15 & - & 15 & 30 & $20,0 \mathrm{~B}$ a & $0,0 \mathrm{D} \mathrm{b}$ \\
\hline 30 & - & 15 & 45 & $35,0 \mathrm{~A} \mathrm{a}$ & $0,0 \mathrm{Db}$ \\
\hline 45 & - & 15 & 60 & $15,0 \mathrm{~B} \mathrm{a}$ & $0,0 \mathrm{D} \mathrm{b}$ \\
\hline 15 & - & - & 15 & $0,40 \mathrm{~B} \mathrm{a}$ & $0,05 \mathrm{~B} \mathrm{~b}$ \\
\hline 30 & - & - & 30 & $0,70 \mathrm{~B}$ a & $0,08 \mathrm{~B} \mathrm{~b}$ \\
\hline 45 & - & - & 45 & $0,88 \mathrm{~B} \mathrm{a}$ & $0,50 \mathrm{~B} \mathrm{~b}$ \\
\hline 60 & - & - & 60 & $0,03 \mathrm{~B}$ a & $0,00 \mathrm{C} \mathrm{b}$ \\
\hline 15 & 15 & - & 30 & $0,75 \mathrm{~B} \mathrm{~b}$ & $2,60 \mathrm{~A}$ a \\
\hline 30 & 15 & - & 45 & $1,38 \mathrm{Ab}$ & $3,18 \mathrm{~A} \mathrm{a}$ \\
\hline 45 & 15 & - & 60 & $0,33 \mathrm{~B} \mathrm{a}$ & $0,00 \mathrm{C} \mathrm{b}$ \\
\hline 15 & - & 15 & 30 & $1,78 \mathrm{~A} \mathrm{a}$ & $0,00 \mathrm{Cb}$ \\
\hline 30 & - & 15 & 45 & $1,65 \mathrm{~A} \mathrm{a}$ & $0,00 \mathrm{C} \mathrm{b}$ \\
\hline 45 & - & 15 & 60 & $0,45 \mathrm{~B} \mathrm{a}$ & $0,00 \mathrm{C} \mathrm{b}$ \\
\hline 15 & - & - & 15 & $1,40 \mathrm{~B} \mathrm{a}$ & $0,20 \mathrm{~B} \mathrm{~b}$ \\
\hline 30 & - & - & 30 & $1,00 \mathrm{~B} \mathrm{a}$ & $0,40 \mathrm{~B} \mathrm{~b}$ \\
\hline 45 & - & - & 45 & $0,90 \mathrm{~B} \mathrm{~b}$ & $1,60 \mathrm{~A} \mathrm{a}$ \\
\hline 60 & - & - & 60 & $0,30 \mathrm{~B} \mathrm{a}$ & $0,00 \mathrm{~B} \mathrm{~b}$ \\
\hline 15 & 15 & - & 30 & $2,50 \mathrm{~A} \mathrm{a}$ & $1,10 \mathrm{~A} \mathrm{ab}$ \\
\hline 30 & 15 & - & 45 & $3,50 \mathrm{~A} \mathrm{a}$ & $2,20 \mathrm{~A} \mathrm{a}$ \\
\hline 45 & 15 & - & 60 & $0,90 \mathrm{~B} \mathrm{a}$ & $0.00 \mathrm{~B} \mathrm{~b}$ \\
\hline 15 & - & 15 & 30 & $1,30 \mathrm{~B}$ a & $0,00 \mathrm{~B} \mathrm{~b}$ \\
\hline 30 & - & 15 & 45 & $2,90 \mathrm{~A} \mathrm{a}$ & $0,00 \mathrm{~B} \mathrm{~b}$ \\
\hline 45 & - & 15 & 60 & $1,30 \mathrm{~B} \mathrm{a}$ & $0,00 \mathrm{~B} \mathrm{~b}$ \\
\hline
\end{tabular}

Médias seguidas pela mesma letra, maiúsculas nas colunas e minúsculas nas linhas, não diferem significativamente entre si pelo teste ScottKnott a $5 \%$ de probabilidade.

carboidratos, com um decréscimo mais pronunciado da porcentagem de sobrevivência nas plantas mantidas a $25^{\circ} \mathrm{C}$ (Figura 1$)$.

Ao final de 180 dias de cultivo a $18^{\circ} \mathrm{C}$, as médias para porcentagem de sobrevivência obtidas em meio suplementado com 15 e $30 \mathrm{~g} \mathrm{~L}^{-1}$ de sacarose $(97,5 \%)$ e $15 \mathrm{~g} \mathrm{~L}^{-1}$ de sacarose combinada com $15 \mathrm{~g} \mathrm{~L}^{-1}$ de sorbitol $(92,5 \%)$ ou manitol $(90,0 \%)$ não diferiram entre si, sendo significativamente superiores aos demais tratamentos. Para porcentagem de folhas verdes, o melhor resultado foi encontrado no tratamento que continha $15 \mathrm{~g} \mathrm{~L}^{-1} \mathrm{de}$ sacarose $(89,1 \%)$, seguido dos meios suplementados com $30 \mathrm{~g} \mathrm{~L}^{-1}$ de sacarose $(71,7 \%)$ e $15 \mathrm{~g} \mathrm{~L}^{-1}$ de sacarose combinado com sorbitol $(73,9 \%)$ (Tabela 1$)$.

$\mathrm{Na}$ temperatura de $25^{\circ} \mathrm{C}$, as médias obtidas para porcentagem de sobrevivência $(89,0 \%)$ e de folhas verdes $(69,7 \%)$ em meio contendo $15 \mathrm{~g} \mathrm{~L}^{-1}$ de sacarose foram significativamente superiores aos demais tratamentos, o que demonstra que na maior temperatura testada o efeito do aumento da concentração de carboidratos foi mais efetivo na redução da viabilidade das plantas de $S$. mucugensis subsp. mucugensis in vitro (Tabela 1).

As menores médias para porcentagem de sobrevivência e de folhas verdes foram obtidas em meio 


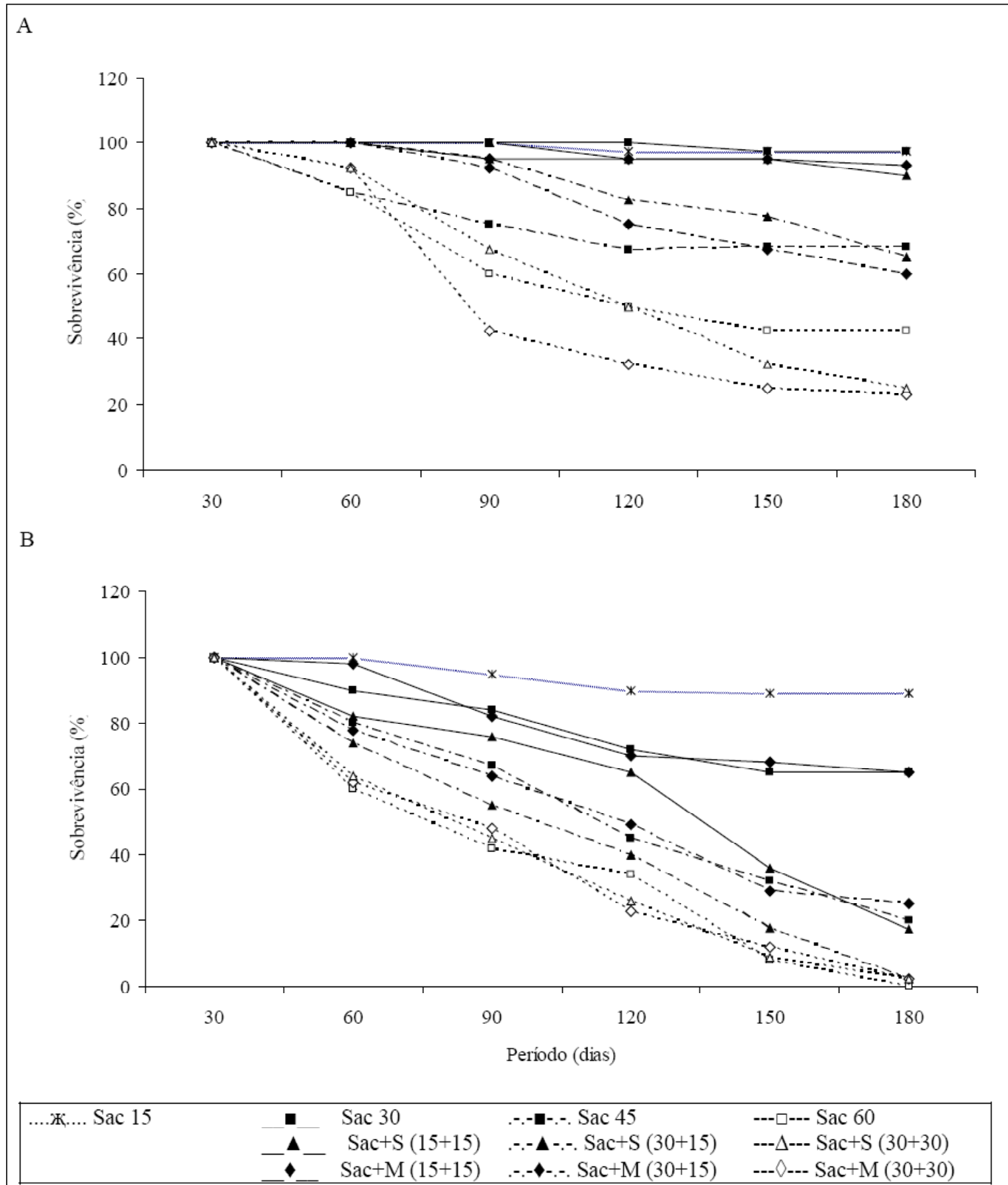

Figura 1 - Efeito de diferentes concentrações dos agentes osmóticos sacarose, sorbitol e manitol sobre a porcentagem de sobrevivência das plantas de $\boldsymbol{S}$. mucugensis subsp. mucugensis conservadas in vitro durante 180 dias, em duas temperaturas: $18^{\circ} \mathrm{C}(\mathrm{A})$ e $25^{\circ} \mathrm{C}(\mathrm{B})$.

contendo manitol, quando comparados com os meios suplementados com sacarose ou sacarose e sorbitol, principalmente nas plantas mantidas a $25^{\circ} \mathrm{C}$ (Tabela 1), o que demonstra que a adição de manitol ao meio nas concentrações testadas é um fator de estresse para o cultivo in vitro da espécie estudada. O decréscimo da sobrevivência das plantas em resposta a adição de manitol ao meio de cultura, também foi relatado para $S$. tuberosum (FORTES \& PEREIRA, 2001).

Comparando as duas temperaturas testadas, as maiores médias para comprimento da parte aérea e da raiz e porcentagem de sobrevivência e de folhas 
verdes, foram obtidas a $18^{\circ} \mathrm{C}$, independente do tipo e concentração de carboidrato utilizado. Apenas nos tratamentos que utilizaram $15 \mathrm{~g} \mathrm{~L}^{-1}$ de sacarose não ouve diferença entre as temperaturas para comprimento da parte aérea e da raiz (Tabela 1). Em geral, temperaturas mais baixas são indicadas para a conservação in vitro por reduzir o metabolismo da planta, o que favorece o crescimento mínimo (LEMOS et al., 2002; LÉDO et al., 2007). Essa estratégia tem sido aplicada com sucesso para a conservação de diversas espécies vegetais, como Saccharum sp., Passiflora giberti N.E. Brown e $\boldsymbol{C}$. nucifera (LEMOS et al., 2002; FARIAet al., 2006; LÉDO et al., 2007).

Neste estudo, a menor temperatura testada não reduziu o crescimento das plantas, mas manteve a viabilidade do material conservado por um período de 180 dias, o que pode estar relacionado à temperatura comumente utilizada para a conservação in vitro de espécies tropicais, que varia entre 15 a $18^{\circ} \mathrm{C}$ (RAO, 2004), ou à temperatura média anual do ambiente de ocorrência natural da espécie estudada, que é de aproximadamente $19,6^{\circ} \mathrm{C}$ (SILVA \& AZEVEDO, 2000)

Assim, a utilização de $18^{\circ} \mathrm{C}$, combinada com a menor concentração de sacarose utilizada $\left(15 \mathrm{~g} \mathrm{~L}^{-1}\right)$, proporcionou a melhor condição para conservação de plantas de S. mucugensis subsp. mucugensis, corroborando os resultados obtidos para Saccharum sp. (LEMOS et al., 2002).

Os resultados obtidos para porcentagem de plantas com brotos, número de brotos por planta e comprimento dos brotos nas plantas mantidas a $18^{\circ} \mathrm{C}$ foram significativamente superiores às médias obtidas a $25^{\circ} \mathrm{C}$ para a maioria das combinações de carboidratos testadas (Tabela 2).

As maiores médias para porcentagem de plantas com brotos e número de brotos por planta, na temperatura de $18^{\circ} \mathrm{C}$, foram observadas em meio contendo $30 \mathrm{~g} \mathrm{~L}^{-1}$ de sacarose combinados com sorbitol (37,5\% e 1,38 respectivamente), ou manitol (35,0\% e 1,65 , respectivamente). Para número de brotos por planta, estes tratamentos não diferiram do meio suplementado com $15 \mathrm{~g} \mathrm{~L}^{-1}$ de sacarose combinado com $15 \mathrm{~g} \mathrm{~L}^{-1}$ de sorbitol $(1,78)$. A $25^{\circ} \mathrm{C}$, médias significativamente superiores para porcentagem de brotos por planta e número de brotos por planta foram obtidas em meios suplementados com 15 e $30 \mathrm{~g} \mathrm{~L}^{-1} \mathrm{de}$ sacarose combinados com sorbitol (Tabela 2).

Nas plantas submetidas a $18^{\circ} \mathrm{C}$, os maiores valores para comprimento do broto foram observados nos tratamentos que continham $15 \mathrm{e} 30 \mathrm{~g} \mathrm{~L}^{-1}$ de sacarose combinado com sorbitol e no meio com $30 \mathrm{~g} \mathrm{~L}^{-1} \mathrm{de}$ sacarose combinado com manitol. A $25^{\circ} \mathrm{C}$, as maiores médias para esta variável foram obtidas nos meios contendo $45 \mathrm{~g} \mathrm{~L}^{-1}$ de sacarose e 15 e $30 \mathrm{~g} \mathrm{~L}^{-1}$ de sacarose combinado com sorbitol (Tabela 2).

É provável que a produção de brotos in vitro em S. mucugensis subsp. mucugensis a partir de planta intacta esteja relacionada ao estresse osmótico causado pela adição de carboidratos ao meio de cultura. Entretanto, não foram encontradas altas taxas de porcentagem de plantas com brotos, número de brotos por explante $\mathrm{e}$ comprimento dos brotos nos meios com os menores potenciais hídricos testados, o que deve estar relacionado à redução da porcentagem de sobrevivência das plantas nestes tratamentos (Tabela 2).

Alterações nas fases de crescimento e reprodução, como a produção de brotos, são estratégias utilizadas pelos vegetais como mecanismo para o escape a seca (LARCHER, 2000). Em $\boldsymbol{S}$. mucugensis subsp. mucugensis, a emissão de brotações e morte da planta na estação seca foi relatada em estudos fenológicos por CERQUEIRA et al. (2008). Assim, a obtenção de brotos em decorrência do déficit hídrico observada neste trabalho reproduz um comportamento natural da espécie na condição ex vitro.

Os resultados obtidos demonstraram o potencial da técnica in vitro para a conservação de $S$. mucugensis subsp. mucugensis. A utilização de meio de cultura MS $1 / 2$ contendo $15 \mathrm{~g} \mathrm{~L}^{-1}$ de sacarose a $18^{\circ} \mathrm{C}$ possibilita a conservação dessa espécie por até 180 dias, sem subcultivo.

\section{REFERÊNCIAS}

CALDAS L.S. et al. Meios nutritivos. In: TORRES, A.C. Cultura de tecidos e transformação genética de plantas. Brasília: Embrapa-CNPH, 1998. p.87-132.

CERQUEIRA, C.O. et al. Fenologia de Syngonanthus mucugensis Giul. subsp. mucugensis e $S$. curralensis Moldenke (Eriocaulaceae), nos municípios de Mucugê e Morro do Chapéu, Chapada Diamantina, BA, Brasil. Acta Botânica Brasílica, v.22, n.4, p.962-969, 2008. Disponível em: <http:// www.scielo.br/pdf/abb/v22n4/a07v22n4.pdf>. Acesso em: 01 jun 2011. doi: 10.1590/S0102-33062008000400007.

DIVAKARAN, M. et al. Conservation of Vanilla species in vitro. Sciencia Horticulturae, v.110, n.2, p.175-180. 2006. Disponível em: <http://www.sciencedirect.com/science/article/ pii/S0304423806002792>. Acesso em: 01 jun 2011. doi: 10.1016/j.scienta.2006.07.003.

ENGELMANN, F. In vitro conservation of tropical plant germoplasma: a review. Euphytica, v.57, p.227-243, 1991. Disponível em: <http://www.springerlink.com/content/ k2gw613148g6637n/>. Acesso em: 01 jun 2011. doi: 10.1007/BF00039669.

FARIA G.A. et al. Sucrose and sorbitol effect in the in vitro conservation of Passiflora giberti NE Brown. Revista Brasileira de Fruticultura, v.28, p.267-270, 2006. Disponível em: <http:/ $/ \mathrm{www}$. scielo.br/scielo.php?script=sci_arttext\&pid=S0100- 
29452006000200025>. Acesso em: 01 jun 2011. doi: 10.1590/ S0100-29452006000200025.

FAY, M.F. In what situations is in vitro culture appropriate to plant conservation? Biodiversity Conservation, v.3, p.176183, 1994. Disponível em: <http://www.springerlink.com/ content/p534k2vn0w34144g/>. Acesso em: 01 jun 2011. doi: $10.1007 / \mathrm{BF} 02291887$.

FERREIRA, D.F. SISVAR Sistema de analises estatísticas. Lavras: UFLA, 2003. V.3, n.4.

FORTES G.R.L.; PEREIRA, J.E.S. Preservação in vitro de batata com ácido acetilsalicílico e duas fontes de carboidrato. Pesquisa Agropecuária Brasileira, v.36, n.10, p.1261-1264, 2001. Disponível em: <http://www.scielo.br/pdf/pab/v36n10/ 6750.pdf.>. Acesso em: 01 jun 2011. doi: 10.1590/S0100204X2001001000007.

GEORGE, E.F. Plant propagation by tissue culture. Part. 1. The technology. 2.ed. Edington, Wilts, London: Exegetics, 1993. $1574 \mathrm{p}$

GIULIETTI, A.M. et al. Estudos em sempre vivas: Taxonomia com ênfase nas espécies de Minas Gerais, Brasil. Acta Botânica Brasílica, v.10, n.2, p.329-377, 1996. Disponível em: <http:/ /kbd.kew.org/kbd/detailedresult>. Acesso em: 01 jun 2011. doi: 328863 .

GONÇALVES S.; ROMANO, A. In vitro minimum growth conservation of Drosophyllum lusitanicum. Biologia Plantarum, v.51, p.795-798, 2007. Disponível em: <http:// www.springerlink.com/content/t761h535380pl20v/ fulltext.pdf>. Acesso em: 01 jun 2011. doi: 10.1007/s10535007-0163-0,

LARCHER, W. Ecofisiologia vegetal. São Carlos: RIMA Artes e Textos, 2000. 531p.

LÉDO, A.S. et al. Efeito da sacarose e do manitol na conservação in vitro por crescimento lento de coqueiro anão. Magistra, v.19, n.4, p.346-351, 2007. Disponível em: <http:/ /www.magistra.ufrb.edu.br/publica/19.4\%20 PDF/ Artigos\%20Magistra\%202007\%20-\%2013.pdf>. Acesso em: 01 jun 2011.

LEMOS, E.E.P. et al. Conservação in vitro de germoplasma de cana-de-açúcar. Pesquisa Agropecuária Brasileiro, v.37, n.10, p.1359-1364, 2002. Disponível em: <http:// www.scielo.br/pdf/\%0D/p67ab/v37n10/13213.pdf>. Acesso em: 01 jun 2011. doi: 10.1590/S0100-204X2002001000002.

LIMA-BRITO, A. et al. In Vitro morphogenesis of Syngonanthus mucugensis Giul. subsp.mucugensis. Ciência e Agrotecnologia, v.35, n.3, p.501-510, 2011. Disponível em: <http://www.editora.ufla.br/site/_adm/upload/revista/35-32011_10.pdf>. Acesso em: 01 jun 2011.

MARTIN, K.P.; PRADEEP, A.K. Simple strategy for the in vitro conservation of Ipsea malabarica an endemic and endangered orchid of the Western Ghats of Kerala, India. Plant Cell, Tissue and Organ Culture, v.74, p.197-200, 2003. Disponível em: <http://www.springerlink.com/content/ t1408853k69x3272/fulltext.pdf>. Acesso em: 01 jun 2011. doi: $10.1023 / \mathrm{A}: 1023971625994$.

MURASHIGE, T.; SKOOG, F. A revised medium for rapid growth and bioassays with tobacco tissue culture. Physiologia
Plantarum, v.15, p.473-497, 1962. Disponível em: <http:// onlinelibrary.wiley.com>. Acesso em: 01 jun 2011. doi: $10.1111 /$ j.13993054.1962.tb08052.x.

NEGASH A. et al. In vitro conservation of enset under slowgrowth conditions. Plant Cell, Tissue and Organ Culture, v.66, n.2, p.107-111, 2001. Disponível em: <http:// www.springerlink.com/content/t20xn $169 \mathrm{nx} 0 \mathrm{v} 876 \mathrm{j} /$ fulltext.pdf>. Acesso em: 01 jun 2011. doi: 10.1023/ A: 1010647905508 .

PEDROSO, A.N.V. et al. In vitro culture at low temperature and $e x$ vitro acclimatization of Vriesea inflata an ornamental bromeliad. Revista Brasileira de Botânica, v.33, n.3, p.407-414, 2010. Disponível em: <http://www.scielo.br/scielo.php?pid=S0100$84042010000300004 \&$ script $=$ sci_arttext $>$. Acesso em: 01 jun 2011. doi: 10.1590/S0100-8404201000030000.

POMPELLI, M.F.; GUERRA, M.P. Ex situ conservation of Dyckia distachya: an endangered bromeliad from South Brazil. Crop Breeding and Applied Biotechnology, v.4, n.3, p.273279, 2004. Disponível em: <http://www.sbmp.org.br/cbab/ siscbab/uploads/c8128f42-3ca0-bf38.pdf>. Acesso em: 01 jun 2011.

RAO, N.K. Plant genetic resources: Advancing conservation and use through biotechnology. African Journal of Biotechnology, v.3, n.2, p.136-145, 2004. Disponível em: <http://www.academicjournals.org/AJB/PDF/Pdf2004/Feb/ Rao.pdf>. Acesso em: 01 jun 2011.

SARASAN, V. et al. Conservation in vitro of threatened plants: progress in the past decade. In Vitro Cellular \& Development Biology Plant, v.42, p.206-214, 2006. Disponível em: <http:/ /www.springerlink.com/content/m8431506w4866408/ fulltext.pdf.>. Acesso em: 01 jun 2011. doi: 10.1079/ IVP2006769.

SARKAR D.; NAIK, P.S. Factors affecting minimal growth conservation of potato microplants in vitro. Euphytica, v.102, p.275-280, 1998. Disponível em: <http://www.springerlink.com/ content/h552135010nu14mp/fulltext.pdf $>$. Acesso em: 01 jun 2011. doi: 10.1023/A:1018309300121.

SILVA G.B.; AZEVEDO, P.V. Potencial edafoclimático da "Chapada Diamantina" no Estado da Bahia para o cultivo de Cítrus. Revista Brasileira de Agrometeorologia, v.8, n.1, p.133-139, 2000 .

SILVA, J.R.S. et al. Efeito da sacarose sobre o enraizamento e desenvolvimento in vitro de Syngonanthus mucugensis Giul. Sitientibus: Série ciências biológicas, v.5, n.2, p.56-59, 2005. Disponível em: <http://www2.uefs.br/revistabiologia/ pg5_n2.html.>. Acesso em: 01 jun 2011.

VILLALOBOS, V.M. et al. The use of biotechnology in the conservation of tropical germoplasma. Biotechnology Advances, v.9, p.197-215, 1991. Disponível em: <http:// www.sciencedirect.com/science/article/pi / 073497509190004F>. Acesso em: 01 jun 2011. doi: 10.1016/ 0734-9750(91)90004-F

WITHERS, L.A.; WILLIANS, J.T. Conservação in vitro de recursos genéticos de plantas. In: TORRES, A.C. et al. (Eds.). Cultura de tecidos e transformação genética de plantas. Brasília: Embrapa-SPI/Embrapa-CBPH, 1998. p.297-330. 